\title{
“QUESTÃ̃ COIMBRÃ": A PROBLEMATIZAÇÃO SOBRE PORTUGAL ATRAVÉS DE UMA POLÊMICA LITERÁRIA PELA GERAÇÃO DE 70 (1865-1866)
}

\author{
"COIMBRA QUESTION": THE PROBLEMATIZATION ABOUT \\ PORTUGAL THROUGH A LITERARY CONTROVERSY BY THE \\ 1870'S GENERATION (1865-1866)
}

DOI: http://dx.doi.org/10.15448/2178-3748.2015.2.20124

\author{
Rômulo de Jesus Farias Brito \\ Doutorando - PUCRS \\ E-Mail: romulojfbrito@hotmail.com
}

\begin{abstract}
RESUMO: Neste trabalho, traça-se uma análise de alguns textos envolvidos na polêmica literária conhecida como "Questão Coimbrã", a fim de identificar as argumentações que embasavam a concepção de intelectuais ligados à chamada "Geração de 70" sobre a sociedade portuguesa oitocentista. Ocorrida entre os anos de 1865 e 1866 em Portugal, a querela opôs distintos posicionamentos sobre a literatura portuguesa e, de forma mais ampla, sobre vários pontos nevrálgicos sobre a situação de Portugal ao final do século XIX. Dentre os envolvidos, encontravam-se Antero de Quental, Teófilo Braga e mesmo Ramalho Ortigão, escritores que defendiam posições como a relação da literatura com as aspirações sociais do período e o respeito à liberdade e individualidade da produção intelectual. Notadamente, estes autores integravam um grupo de intelectuais conhecido como "geração de 70" ou "geração nova", que iniciou sua atuação política e literária na transição das décadas de 1860 e 1870 visando uma mudança na forma de se conceber a sociedade portuguesa e a superação de uma decadência que teria se instaurado no país. Dessa forma, pretende-se compreender quais os parâmetros e modelos empregados por estes intelectuais durante a "Questão Coimbrã" na interpretação e no projeto de transformação sociocultural em Portugal. Para tanto, serão analisados os principais textos produzidos na polêmica literária, com ênfase nos escritos elaborados pelos intelectuais citados.
\end{abstract}

Palavras-Chave: Geração de 70, Polêmica Literária, História de Portugal.

\begin{abstract}
In this paper, we draw an analysis of some texts involved in literary controversy known as "Questão Coimbrã" (Coimbra Question) in order to identify the arguments that informed the ideas of intellectuals linked to the so-called "Geração de 70" (1870's generation) on the nineteenth-century Portuguese society. Occurred between 1865 and 1866 in Portugal, the quarrel opposed positions on different central points on the situation of Portugal in the late nineteenth century. Among those involved, found themselves Antero de Quental, Teófilo Braga and even Ramalho Ortigão, writers who held positions as the relationship of literature with social aspirations of the period and the respect for freedom and individuality of intellectual production. Notably, these authors were part of a group of intellectuals known as " 1870's generation" or "New generation", who began his political and literary work in the transition from the 1860 and 1870 decades towards a change in the way of conceiving the portuguese society and overcoming a decline that would have brought the country. The aim is to understand which parameters and models employed by these intellectuals during the "Coimbra Controversy" in the interpretation and the sociocultural transformation project in Portugal. Therefore, the main texts involved in literary controversy will be analyzed, with emphasis on the writings produced by Antero de Quental, Teófilo Braga and Ramalho Ortigão.
\end{abstract}

Keywords: 1870’s Generation, Literary Controversy, History of Portugal 


\section{Introdução}

As polêmicas entre escritores observadas na imprensa foram, conhecidamente, um dos principais instrumentos empregados na produção intelectual no século XIX. Para além das disputas pessoais, constituíam-se em uma poderosa ferramenta de promoção de uma obra, de divulgação de ideias e defesa de posicionamentos políticos. Neste sentido, uma disputa escrita pode tornar-se um interessante recorte para se pensar, dentre outras coisas, as distintas formas de se conceber a literatura ou interpretar a situação de uma nação em determinado período. Em Portugal ao final dos Oitocentos, talvez um dos melhores exemplos do potencial de análise das polêmicas literárias como escopo para reflexões mais amplas seja a controvérsia travada em meados da década de 1860.

Deu-se o nome de "Questão Coimbrã" às querelas observadas entre intelectuais portugueses a partir de uma série de poemas, artigos em periódicos e cartas abertas publicadas nos anos de 1865 e 1866, que acabaram por expor divergências nas formas de se pensar a literatura portuguesa e, de forma mais ampla, a situação de Portugal ao final do século XIX. O adjetivo que a denominou está diretamente ligado à Universidade de Coimbra, local de formação dos principais envolvidos e da publicação de alguns de seus escritos.

A disputa orbitou sobre a temática da escrita literária portuguesa em meados do século XIX. Apesar de ser o objeto desencadeador da polêmica, no entanto, a literatura acabou por tornar-se um dentre outros temas que se apresentaram no decorrer da polêmica. As necessidades morais e intelectuais do público, o estatuto do intelectual, a sua independência face aos poderes estabelecidos, o fundamento e estrutura de um "espírito crítico", assim como de uma "reforma mental" em Portugal foram alguns dos temas diretos abordados pelos textos da "Questão Coimbrã” (FERREIRA e MARINHO, 1989, p.15).

Os principais envolvidos na controvérsia demarcaram em seus discursos posições que permitem, a título desta análise, pensá-los a partir de dois lados opositores. Em um, encontrava-se Antônio Feliciano de Castilho e escritores sob sua influência, como Manuel Joaquim Pinheiro Chagas, que representariam o que seria a forma instituída e dominante de produção literária portuguesa em meados do século XIX. Do outro, estavam Antero de Quental e Teófilo Braga, cujos escritos questionavam tal forma e apontavam para outro caminho de reflexão para a literatura portuguesa.

A posição destes últimos em relação à literatura se enquadra em um grande processo de problematização da cultura e sociedade portuguesa, e de Portugal enquanto nação, que 
apesar de preceder o Oitocentos, ganhou força durante o século XIX. Este questionamento ganhou contornos específicos na transição das décadas de 1860 para 1870 , quando passou a ser realizado por um grupo de jovens intelectuais que viria a ser conhecido por sua atuação política, jornalística e literária.

No início da década de 1860, os nomes de Antero de Quental, Teófilo Braga, Ramalho Ortigão, Eça de Queiroz e Oliveira Martins, dentre outros, começavam a se destacar por suas obras literárias, publicações periódicas e engajamento político. Em seus escritos, eram tecidas diversas críticas à forma como a política, a economia e a construção do conhecimento eram conduzidas em Portugal, propondo uma revisão de como a realidade portuguesa deveria ser pensada em diversas esferas, da escrita de sua história à sua organização social. $\mathrm{O}$ questionamento destes escritores seguia a esteira de conhecidos intelectuais como Alexandre Herculano e Almeida Garret, mas ganhou distintos contornos em suas obras a partir das correntes teóricas e doutrinas políticas que ascenderam em meados do século XIX, período de suas formações.

Constantemente designados sob a alcunha de "Geração de 70" ou "Geração Nova", estes indivíduos apresentaram, apesar da aparência uniforme de sua designação, uma heterogeneidade em relação às suas influências teóricas e aos caminhos que propunham para Portugal. Entretanto, suas ações eram ligadas por dois pontos comuns. O primeiro era o diagnóstico de que Portugal apresentava uma profunda decadência em várias esferas da sociedade, que se estendia de sua estruturação política e econômica até sua produção científica e artística $^{1}$. O segundo fundamento era de que quaisquer ações para modificar tal situação deveriam passar por uma reflexão da realidade portuguesa a partir das transformações observadas em outros países europeus. Tais concepções mobilizavam a argumentação destes intelectuais.

As críticas tecidas por Antero e Teófilo no âmbito da "Questão Coimbrã", posteriormente reforçadas pela atuação de outros intelectuais, foram consideradas como a primeira oposição sistemática, aberta e contundente contra uma determinada estética literária que teria se instaurado em Portugal $^{2}$. Mais especificamente, o questionamento centrava-se em

\footnotetext{
${ }^{1}$ Como afirma PIRES, a decadência apresenta-se mais como um "sentimento" ou noção que embasa a obra destes autores do que um conceito articulado e bem definido. (PIRES, 1992, p.23). CALAFATE, por outra via, afirma que a consciência de uma decadência se acentuou no século XIX e que uma distância cultural em relação à Europa "transpirinenaica" foi ainda mais ressaltada. (CALAFATE, 2006, p.13)

2 LOPES e SARAIVA consideram a "Questão Coimbrã" como o primeiro sinal de renovação literária e ideológica em Portugal a partir de novos sistemas de ideias que passaram a circular na Europa em meados do séc. XIX, como o(s) positivismo(s), socialismo(s), a influência da obra de Darwin nas interpretações sociais, dentre outras (LOPES e SARAIVA, 1975, p.896). PAREDES também nota que é "pacífica a consideração da
} 
uma forma de escrita literária de influência romântica que se seguiu após as obras de nomes como Alexandre Herculano e Almeida Garret, mas que não teria acompanhado a profundidade da obra de seus antecessores. Esta produção teria mistificado os temas centrais de inspiração romântica, tornando seus escritos em repositórios de alusões aos amores desesperados, às melancolias difusas, ao tédio da existência e ao historicismo por fatalidade (HOMEM, 2005, pp.27-28), constituindo o que Teófilo Braga chamou de "ultrarromantismo".

Para além da literatura, as críticas de Antero e Teófilo recaíram sobre uma forma de se pensar acerca de Portugal que teria se enraizado não apenas na escrita literária, mas em todas as áreas da vida pública, em instituições e mesmo no comportamento do povo português em todo o território. Segundo seus julgamentos no caso específico da literatura, esta não conseguia refletir sobre os principais problemas do cotidiano português e não acompanhava as transformações técnicas e culturais observadas em outros países, pautando-se na reprodução, nos elogios mútuos e vazios entre literatos e na falta de criticidade, o que representaria, em última instância, a situação de decadência do país. Desta maneira, os argumentos empregados na "Questão Coimbrã" estão carregados de diversas referências sobre como estes intelectuais diagnosticavam a decadência portuguesa, quais eram os modelos de desenvolvimento que deveriam ser observados pelos portugueses e os possíveis caminhos para uma mudança.

Quais os argumentos utilizados por estes intelectuais? Como percebiam a situação da produção literária e artística portuguesa de então? Como a literatura tornou-se base para a explanação de suas concepções sobre a decadência de Portugal? Quais os problemas por eles apontados e os parâmetros para a transformação pretendida neste momento específico no país? É com base nestes questionamentos que este estudo foi desenvolvido.

A presente análise pretende compreender, a partir da polêmica literária, quais eram os fundamentos norteadores das interpretações de alguns membros da "Geração de 70", notadamente Antero e Teófilo, sobre a sociedade portuguesa ao final do século XIX. Pretende entender, por conseguinte, qual o diagnóstico operado sobre a situação de Portugal e quais os possíveis caminhos de sua superação nos escritos destes intelectuais.

$\mathrm{Na}$ medida em que narra o desenvolvimento da polêmica, este artigo se debruçará sobre as principais publicações envolvidas na "Questão Coimbrã", com grande ênfase nos escritos elaborados por Antero de Quental e Teófilo Braga. A fim de apontar também para a heterogeneidade da "Geração de 70" e ressaltar a complexidade de seus escritos, será

célebre Questão coimbrã como o marco inicial do movimento de contestação das ideias estabelecidas em Portugal" por parte da "geração de 70". (PAREDES, 2013, p.141)

Oficina do Historiador, Porto Alegre, EDIPUCRS, v. 8, n. 2, jul./dez. 2015, p. 154-173 
brevemente analisado no segmento final um texto composto por Ramalho Ortigão por ocasião do debate.

\section{O preâmbulo da contenda}

A crítica que levou ao início da polêmica se deu sobre alguns escritos poéticos de Antero de Quental e Teófilo Braga produzidos no início de sua atuação literária. Três deles tiveram maior repercussão devido às ideias que veiculavam sobre a função da poesia e, por extensão, da literatura em relação à sociedade. Apesar de tratarem preponderantemente da escrita literária, estas obras não podem ser desvinculadas dos projetos político-culturais de seus autores e da contestação que começava a se dar sobre a situação de Portugal neste momento.

Em 1864, Teófilo Braga publicou duas obras com composições poéticas intituladas Visões dos Tempos e Tempestades Sonoras. Nelas, o autor buscou a elaboração de uma história ideal da humanidade por meio da poesia, que a atrelasse diretamente a outras artes e esferas do conhecimento, acompanhando o desenvolvimento da sociedade onde fosse produzida. Através da composição poética e pensando a história da literatura em estágios, Teófilo realizou uma abordagem que ia da Grécia antiga ao cristianismo contemporâneo, trazendo considerações sobre a estética literária, a relação entre sentimento e forma, dentre outros aspectos. Segundo o autor, "determinar as evoluções mais características da poesia para estudá-la também pela sua face ideal" era o principal objetivo de suas composições. (BRAGA, 1864, p.VIII)

Odes Modernas, por sua vez, foi publicada por Antero de Quental em agosto de 1865, reunindo poemas de sua autoria em que foram tratados temas como as monarquias, as instituições religiosas, a liberdade e a verdade, precedidos pela epígrafe “l'idee...c'est dieu”. A escolha destas temáticas não se deu por acaso, integrando pontos que o autor considerava basilares na reflexão sobre a sociedade portuguesa.

Entretanto, a repercussão dos versos foi igualada e mesmo superada por uma nota explicativa adicionada por Antero ao final da obra, na qual visou conferir um sentido para a produção de seu livro e exprimiu parte de sua concepção acerca da função da literatura na sociedade. Neste segmento de sua obra, o autor afirmou inicialmente que: 
Este livro é uma tentativa, em muitos pontos imperfeita, seguramente, mas sempre sincera, para dar à poesia contemporânea a cor moral, a feição espiritual da sociedade moderna, fazendo-a assim corresponder à alta missão que foi sempre a da Poesia em todos os tempos (...) - isto é, a forma mais pura daquelas partes soberanas da alma coletiva de uma época, a crença e a aspiração. (QUENTAL, 1865b, p.151)

Neste trecho, destaca-se o papel atribuído por Antero à poesia, colocando-a como uma fundamental forma de expressão de uma coletividade, cuja escrita e análise não deveria ser desvinculada do local de onde partira. Deduz-se dessa posição, apesar de não explícito, a função e responsabilidade do "homem de letras", poetas e romancistas, que seriam então os responsáveis por esta expressão e que se perpetuariam, portanto, como vozes de uma suposta "essência" dos povos ou nações.

Antero expressou, desde o início, seu desejo em colocar a poesia portuguesa a par da realidade que, segundo seu julgamento, caracterizaria a sociedade moderna. Evidencia-se então uma concepção de literatura que deveria deixar a busca por uma perfeição estética para enfocar seu conteúdo e papel intrínseco enquanto possível agente tradutor e transformador de uma época.

O trecho a seguir toca mais especificamente em algumas das questões que o autor considerava como elementares em tal transformação. Neste, o autor manifestou sua concepção sobre os pontos com os quais a poesia moderna deveria estar ligada e quais deveria combater:

Reconstrução do mundo humano sobre as bases eternas da Justiça, da Razão e da Verdade, com exclusão dos Reis e dos Governos tirânicos, dos Deuses e das Religiões inúteis e ilusórias - é este o mais alto desejo, a aspiração mais santa desta sociedade tumultuosa que uma força irresistível vai arrastando, ainda contra vontade, em demanda do mistério tremendo do seu futuro. (...) A poesia que quiser corresponder ao sentir mais fundo do seu tempo, hoje, tem forçosamente de ser uma poesia revolucionária. Que importa que a palavra não pareça poética às vestais literárias do culto da arte pela arte? No ruído espantoso do desabar dos Impérios e das Religiões, há ainda uma harmonia grave e profunda para quem a escutar com a alma penetrada do terror santo deste mistério que é o destino das Sociedades! (QUENTAL, 1865b, pp.159-160)

Os ideais que Antero concebia como fins últimos aos que a sociedade contemporânea almejaria ficam claramente expressos neste segmento. Tendo como máximas a "justiça", "razão" e "verdade", as nações deveriam alcançar uma constituição social pautada no pensamento racional e na real igualdade entre os direitos dos homens, caminho que teria como obstáculos as monarquias e algumas instituições religiosas. O combate ao poder 
centralizado da monarquia portuguesa e à Igreja Católica viria a se tornar uma constante na atuação literária e política do autor. Tendo em vista tal movimento, a poesia deveria adquirir uma postura "revolucionária" a fim de acompanhar e traduzir estas transformações.

O sentido do termo atribuído à poesia pelo autor não pode ser desvinculado de suas influências teóricas, dentre as quais a filosofia política de alguns intelectuais ligados às doutrinas do(s) socialismo(s), como Pierre-Joseph Proudhon ${ }^{3}$. A noção específica de "revolução" empregada por Antero em relação ao papel da expressão poética na sociedade portuguesa atrela à transformação política uma profunda mudança cultural. A literatura, representada neste segmento pela poesia, seria apontada por alguns autores da "Geração de 70" como um dos caminhos para o desenvolvimento de uma visão crítica e racional da realidade, considerada por eles como um dos requisitos para a superação do estado de decadência em que Portugal se encontraria.

Estes escritos de Antero e Teófilo chamaram a atenção da imprensa e de intelectuais do período, começando a conferir destaque à atuação literária destes dois escritores ligados à “Geração de 70". É especialmente com vistas sobre estes textos que críticas foram tecidas por alguns intelectuais já conhecidos no período, desencadeando a polêmica literária que prosseguiria pelos seguintes meses.

\section{O estopim da polêmica}

Posteriormente às publicações de Odes Modernas e Visões dos Tempos, Manuel Pinheiro Chagas ${ }^{4}$ escreveu diversos artigos no Jornal do Comércio e no Comércio do Porto sobre os caminhos adotados por Antero e Teófilo em sua crítica literária. Em alguns momentos, referências a seus nomes eram realizadas de forma mais branda. Em outros, Pinheiro Chagas atribuía aos autores uma tentativa excessiva de demonstrar erudição, especialmente no que se referia a Teófilo, e uma "superficialidade" de suas análises literárias. $\mathrm{Na}$ crítica de 11 de agosto no Jornal do comércio, Pinheiro Chagas apontou para as considerações de Antero e Teófilo como essencialmente formais e estilísticas, que se valeriam

\footnotetext{
${ }^{3}$ Pierre-Joseph Proudhon (1809-1865) foi um conhecido filósofo francês, ligado diretamente à filosofia política das interpretações socialistas e considerado como um dos principais teóricos do anarquismo. Vários pontos de sua obra influenciaram o início da atuação de intelectuais da "Geração de 70”, como Antero de Quental e Eça de Queiroz.

${ }^{4}$ Manuel Joaquim Pinheiro Chagas (1842-1895) foi um escritor, jornalista e político português. Atuou em vários periódicos, além de ter exercido os cargos de deputado, par do reino e Ministro da Marinha e Ultramar.
}

Oficina do Historiador, Porto Alegre, EDIPUCRS, v. 8, n. 2, jul./dez. 2015, p. 154-173 
de expressões vazias como recursos textuais (CHAGAS apud FERREIRA e MARINHO. 1988, p.59).

- As afirmações de Pinheiro Chagas geraram reações por parte de escritores como Germano Meireles, que defendeu o papel inovador de Odes Modernas, e de Olímpio de Freitas, defendendo a poesia de Teófilo Braga ${ }^{5}$. Entretanto, foram as palavras de Antônio Feliciano de Castilho que geraram maior comoção por parte de Antero e Teófilo.

Vindo a tornar-se figura central na Questão Coimbrã, Antônio Feliciano de Castilho era tido como referência entre os jovens escritores de influência romântica. Graduado pela Faculdade de Cânones na Universidade de Coimbra, foi autor de obras que apresentavam elementos estéticos do arcadismo e romantismo, sendo também um dos criadores e diretores da Revista Universal Lisbonense, um dos principais periódicos vinculados ao romantismo em Portugal. Sua imagem de gênio literário foi reforçada pelo fato de ter exercido toda sua formação e atuação profissional praticamente sem a visão, em grande parte perdida aos seis anos em decorrência de um surto de sarampo.

A contenda foi desencadeada a partir da publicação de Poema da Mocidade, de Manuel Joaquim Pinheiro Chagas, em outubro de 1865. Logo após a capa, a obra traz uma dedicatória a Antônio Feliciano de Castilho. Pinheiro Chagas dedicou sete páginas de agradecimento ao escritor, de quem se considerava um "admirador, amigo e discípulo obrigadíssimo" (CHAGAS, 1865, p.XIII). De certa forma, a recíproca a tais palavras já se encontrava presente na mesma obra, em um posfácio assinado pelo próprio Antônio Feliciano de Castilho.

O texto que sucedia a obra, escrito em forma de carta a Antônio Maria Pereira, proprietário da editora responsável pela publicação, foi intitulado Carta do Ilustríssimo e Excelentíssimo Sr. Antônio Feliciano de Castilho ao Editor. O objetivo principal do documento era a apreciação sobre Pinheiro Chagas, cuja produção literária recebeu diversos elogios de Castilho. Além disto, o autor sugeriu sua nomeação enquanto professor interino da cadeira de Literatura Moderna da Universidade de Coimbra antes da elaboração do concurso para a escolha do professor permanente, devido às qualidades que observara no escritor.

Para além de Pinheiro Chagas, Castilho realizou uma crítica literária sobre outros pontos, fazendo comentários acerca da escrita contemporânea em Portugal. Nestas reflexões, foram feitas referências indiretas a obras, mas citação direta a atitudes de alguns jovens escritores que começavam a ascender por meio de obras anteriormente publicadas. Os

\footnotetext{
${ }^{5} \mathrm{O}$ conteúdo destes escritos pode ser encontrado na compilação realizada por Alberto Ferreira e Maria José
} Marinho. (FERREIRA e MARINHO, 1988)

Oficina do Historiador, Porto Alegre, EDIPUCRS, v. 8, n. 2, jul./dez. 2015, p. 154-173 
intelectuais em questão são Antero de Quental e Teófilo Braga, além da menção, com menor ênfase, a José Cardoso Vieira de Castro ${ }^{6}$.

O ponto central das críticas de Castilho era o que considerava como duras e desnecessárias palavras utilizadas pelos intelectuais em críticas literárias, direcionadas a nomes ligados à literatura e outras esferas públicas portuguesas. Tais posturas se originariam, segundo ele, em uma precipitação típica da imaturidade e juventude que a idade viria a corrigir. Vieira de Castro foi referido de forma mais branda e até elogiosa, mas os nomes de Antero e Teófilo recebem críticas e são vistos com indiferença em relação a suas atuações literárias. Tratados como excessivamente idealistas, Castilho afirma em determinado momento que sobre "Braga e Quental, de quem, pelas alturas em que voam, confesso, humilde e envergonhado, que muito pouco enxergo, nem atino para onde vão, nem avento o que será deles afinal.” (CHAGAS, 1865, p.215)

Castilho adicionou em Post Scriptum um aviso aos que pudessem discordar de suas opiniões e viessem a manifestar-se em público de que ele não as responderia, tendo dito tudo o que pensava sobre as questões tratadas. Mas a ressalva, entretanto, não impediu que a resposta viesse de forma incisiva por parte de Antero e Teófilo, gerando os textos que demarcariam a ruptura entre as duas percepções sobre a produção intelectual em Portugal e definiriam a "Questão Coimbrã".

\section{As reações de Antero e Teófilo}

Em resposta às opiniões de Castilho, Antero de Quental publicou em forma de carta aberta o folhetim chamado Bom senso e bom gosto em novembro de 1865 . O título deste texto, um dos mais conhecidos da "Questão Coimbrã”, também é comumente utilizado em denominação à polêmica literária. Como uma réplica direta à “carta ao editor", este manifesto passou a mencionar diretamente Antônio Feliciano de Castilho, apontando para sua obra literária e o que este representaria para a atual situação da literatura portuguesa.

Ao tratar do caso específico que desencadeou a polêmica, este escrito fez várias citações do que seriam, para Antero de Quental, as referências em termos de produção de conhecimento, o oposto do caminho então seguido por Portugal. São mencionados autores,

\footnotetext{
${ }^{6}$ José Cardoso Vieira de Castro (1837-1872) foi um escritor e político português, vereador pelo município de Fafe e deputado. Atuou como colaborador em diversos periódicos portugueses, com escritos voltados para a temática política em Portugal. Foi membro da Academia Real das Ciências de Lisboa e esteve envolvido em vários questionamentos às estruturas e condutas de diretores e professores da Universidade de Coimbra durante seu período de estudante.
}

Oficina do Historiador, Porto Alegre, EDIPUCRS, v. 8, n. 2, jul./dez. 2015, p. 154-173 
movimentos intelectuais e países que representariam para este autor o que de mais contemporâneo haveria sobre a reflexão da sociedade oitocentista. Desta forma, a análise de sua construção fornece vários argumentos do que seria o diagnóstico de Antero sobre Portugal e sua situação em várias áreas do conhecimento.

Dentre os pontos utilizados por Antero em suas críticas, está a relação da obra de Castilho com a poesia da antiguidade clássica, tanto na temática quanto na forma, além da sua posição central dentro do que considerava ser uma "escola de elogios mútuos" que teria se estabelecido na escrita literária portuguesa.

Não é traduzindo os velhos poetas sensualistas da Grecia e de Roma; requentando fabulas insossas diluidas em milhares de versos semsabores; não é com idyllios grotescos sem expressão nem originalidade, com allusões mitológicas que já faziam bocejar nossos avós; com frases e sentimentos postiços de academico e retórico; com visualidades infantis e puerilidades vãs; com prosas imitadas das algaravias místicas de frades estonteados; com banalidades; com ninharias; não é, sobre tudo, lisongeando o mau gosto e as pessimas ideias das maiorias, indo atrás delas, tomando por guia a ignorancia e a vulgaridade, que se hão de produzir as ideias, as sciencias, as crenças, os sentimentos de que a humanidade contemporanea precisa para se reformar como uma fogueira a que a lenha vai faltando. (QUENTAL, 1865a, p.11)

De forma direta, o questionamento de Antero recaiu sobre o que pensava ser a infertilidade de uma escrita que retomava e repetia modelos clássicos na composição literária. Para o autor, nada de realmente inovador teria se apresentado nas últimas décadas, tendo a literatura estagnado em uma excessiva preocupação com a forma e exaltação dos sentimentos. A crítica e o diagnóstico, entretanto, expandem-se para além da situação da literatura portuguesa. Pensado de forma ampla, toda a produção intelectual em Portugal, que incluiria as artes e ciências, teria se prendido a uma reprodução acrítica de velhos modelos e no culto a determinados estilos.

Em Portugal, esta prática teria se institucionalizado, dentre outras causas, por uma ausência de debates acerca da literatura, que se diluiria totalmente em meio à "escola de elogios mútuos" da qual Castilho seria o principal expoente. O caminho para a literatura portuguesa e, amplamente, para o desenvolvimento do país, seria, segundo Antero, a constante reflexão sobre as transformações que ocorreriam fora e dentro de Portugal, às quais toda forma de produção intelectual deveria corresponder, e a busca pela constante inovação técnica e artística, acompanhando o desenvolvimento da sociedade. 
Esta defesa não estava ligada apenas às específicas críticas realizadas por Castilho ou à construção literária portuguesa, mas à liberdade de toda manifestação intelectual no país. Um dos principais pontos apontados como críticos no país e ligado à sua decadência seria uma ausência da livre expressão de posicionamento políticos, artísticos e científícos. Predominaria um cerceamento de opiniões que se opusessem às instituições públicas ou personalidades da política e literatura portuguesa. Algumas das palavras publicadas por Castilho representariam para Antero não apenas um ataque direto à sua produção, mas um exemplo de coerção ao "livre pensamento", um dos principais suportes para a superação do estado em que se encontraria Portugal em sua concepção.

Posteriormente, Antero se deteve em outro ponto da crítica realizada por Antônio Feliciano de Castilho. Este afirmara que os escritos de Antero e Teófilo estariam totalmente deslocados da realidade da escrita literária, encontrando-se em um plano completamente idealista. De forma irônica, o autor de Odes Modernas passou a descrever brevemente a situação da produção em outros países, dando fundamentais exemplos dos modelos que Portugal, em sua concepção, deveria seguir:

Todavia, quem pensa e sabe hoje na Europa não é Portugal, não é Lisboa, cuido eu: é Paris, é Londres, é Berlim. Não é a nossa divertida Academia das Ciências, que revolve, decompõe, classifica e explica o mundo dos factos e das ideias. É o Instituto de França, é a Academia Científica de Berlim, são as escolas de filosofia, de história, de matemática, de física, de biologia, de todas as ciências e de todas as artes, em França, em Inglaterra, em Alemanha. Pois bem: a Alemanha, a Inglaterra, a França, comprazem-se no nevoeiro, são incompreensíveis e ridículas, são metafísicas também. As três grandes nações pensantes são risíveis diante da crítica fradesca do sr. Castilho. Os grandes gênios modernos são grotescos e desprezíveis aos olhos baços do banal metrificador português. (QUENTAL, 1865a, p.11-12)

Logo no início, Antero demarcou os três países que estariam à frente de Portugal em diversas esferas e seriam os centros de referência no que tange à produção intelectual. França, Inglaterra e Alemanha deveriam ser os modelos a serem seguidos. Com suas instituições científicas e artísticas, estas nações teriam se destacado em várias áreas do conhecimento. A argumentação tecida pelo autor era de que, segundo os parâmetros estabelecidos por Castilho em sua crítica, as recentes obras encontradas nestes países também teriam aspirações "metafísicas" ou excessivamente idealistas, sendo ridicularmente descartadas pelo "metrificador", adjetivo conferido para ressaltar novamente a excessiva preocupação com a forma. 
Esta posição foi corroborada em afirmação posterior, quando Antero, ao seguir o tom irônico empregado, citou os exemplos de intelectuais e de correntes de pensamento que considerava como expoentes de uma moderna concepção de mundo e "tradutores" da experiência social contemporânea.

O grande espírito philosophico do nosso tempo, a grande creação original, immensa da nossa edade, não passa de confusão e embroglio desprezivel para o professor de ninharias, que cuida que se fustiga Hegel, Stuart Mill, Augusto Comte, Herder, Wolff, Vico, Michelet, Proudhon, Littré, Feuerbach, Creuzer, Strauss, Taine, Renan, Buchner, Quinet, a philosophia allemã, a critica franceza, o positivismo, o naturalismo, a historia, a methaphysica, as immensas creações da alma moderna, o espirito mesmo da nossa civilização.... que se fustiga tudo isto e se ridicularisa e se derriba com a mesma sem-cerimonia com que elle dá palmatoadas nos seus meninos de 30, 40 e 50 annos, de Lisboa, do Gremio, da Revista Contemporanea! (QUENTAL, 1865a, p.12)

O grupo predominante na produção literária portuguesa, encabeçado por Castilho, refutaria algumas das principais obras científicas e literárias escritas no século XIX, cuja elaboração foi realizada especialmente na França, na Inglaterra e na Alemanha. A lista dos nomes listados por Antero aponta, para além de suas influências particulares, uma grande pluralidade de posicionamentos teóricos e áreas de atuação, englobando filosofias políticas, teorias de interpretação social, movimentos estéticos, análises do mundo físico, escrita da história e além. Todos eles teriam em comum, no entanto, o ato de repensar as organizações sociais e o conhecimento a partir de uma perspectiva racional e alinhada às necessidades da sociedade, propondo constantemente novos caminhos de reflexão que seriam um dos fundamentos do saber moderno.

Antero seguiu sua linha narrativa, ironizando o que seria a posição contrária de Castilho a todos os modelos e inovações interpretativas modernas que discordassem de sua visão de mundo:

Quem seguir com tudo isso vai com o pensamento moderno; com as tendências da ciência; com o resultado de trinta anos de crítica; com a nova escola histórica; com a renovação filosófica; com os pensadores; com os sábios; com os gênios; vai com a França; vai com a Alemanha - mas que importa? Não vai com o sr. Castilho! Não vai com o novo método repentista! Não vai com o moderno folhetim português! (QUENTAL, 1865a, p.12) 
Em suas considerações finais, Antero falou da dureza das palavras que empregou, transitando entre termos como "futilidade" e "pequenez", cuja justificativa orbitava na atual situação da literatura que seria endossada pelas ações de Castilho. Sua carta se encerrava com sua assinatura, precedida das palavras "nem admirador, nem respeitador", contrariamente às palavras usadas por Pinheiro Chagas na introdução da obra que desencadeou a polêmica.

De forma não menos combativa, Teófilo Braga também posicionou-se em resposta direta a Castilho, inserindo na contenda o texto As Teocracias Literárias, também em novembro de 1865 , cujo título aponta para a concepção do autor sobre a atual situação da literatura portuguesa. Teófilo endossou a crítica realizada por Antero em Bom senso e bom gosto, cujo escrito julgava vir "a ser um capítulo da história da literatura contemporânea" (BRAGA, 1865, p.8), e criticou duramente a posição de Castilho frente às propostas de novos caminhos para a literatura portuguesa, ato que julgava ser a demonstração da tentativa de estabelecimento de uma "teocracia" na produção literária portuguesa:

A grande individualidade, resultado dos progressos deste século, vai tornando impossível todas as supremacias, tanto na religião, como no estado, como na arte. É para onde confluem todos os esforços, todas as lutas; é o móbil de ação na Europa moderna. (...) Contudo, entre nós, como se vê pelas suas obras, ou talvez por esta infância perpétua que lhe encontram os seus admiradores, que é essencialmente imitadora, procura também no último quartel da vida aclamar-se o árbitro supremo da literatura, e cobrir com os retalhos da sua púrpura as chagas e aleijões dos áulicos, decretando-lhes a admiração pública, e impondo-lhes à posteridade. (...) O aparecimento de um livro é uma das melhores tertúlias para o Sr. Castilho; aparece como estes homens que vão a todos os enterros. (BRAGA, 1865, pp.5-7)

A grande defesa de Teófilo recaiu sobre a liberdade e individualidade das manifestações intelectuais em Portugal. $\mathrm{O}$ autor observou na pluralidade de posicionamentos políticos e intelectuais detectada em outros países europeus ao longo do século XIX uma total obsolescência e impraticabilidade da manutenção de qualquer soberania na vida pública em várias esferas, da política às artes. O trecho, notadamente, faz direta referência ao que seria a posição de Castilho frente a obras que divergissem do que ele e os escritores sob sua influência praticavam na literatura, como as de Antero e Teófilo, e ao pedido para que Pinheiro Chagas ocupasse a cadeira de Literatura Moderna interinamente.

Teófilo atacou diretamente a figura de Castilho, acusando-o de tentar exercer uma posição de "árbitro literário" devido ao destaque que possuíra na literatura portuguesa nas últimas décadas. À juventude que o cegamente seguira, é atribuída uma postura 
essencialmente imitadora e reprodutiva, elemento considerado como um dos principais pontos de decadência da produção intelectual portuguesa. A defesa pela individualidade e igualdade da intelectualidade portuguesa segue:

Essa frase usual da república das letras significa mais do que se pensa; a inteligência não reconhece majestades, nem hierarquias, vive da igualdade plena, e tanto, que é este o dom maravilhoso da razão, a uniformidade de processos para uma igualdade de resultados - a verdade. (BRAGA, 1865, p.7)

O sentido de "república", empregado em referência ao ideal almejado da construção do conhecimento, aparece atrelado à noção de igualdade e liberdade, fundamento do que deveria ser, na concepção de Teófilo, a produção do saber em Portugal, livre de qualquer censura ou favorecimento e baseada apenas no mérito individual. Ligado ao sentido de liberdade e igualdade, a razão aparece como base deste conhecimento, cujo objetivo deveria ser a busca pela verdade. Teófilo observa em Portugal o quadro contrário, no qual um dos grandes empecilhos para o desenvolvimento seriam práticas como as de Castilho.

Após as respostas de Antero e Teófilo, outros escritos foram publicados, ainda em 1865 , pelos principais atores envolvidos na polêmica. Pinheiro Chagas responderia à carta de Antero ainda em novembro com Bom senso e bom gosto, folhetim à propósito da carta que o senhor Antero de Quental Dirigiu a Antônio Feliciano de Castilho. Em dezembro, o próprio Antero publicaria $A$ dignidade das letras e as literaturas oficiais. Entretanto, para o fim proposto pela presente análise, cabe a atenção a um texto publicado por um outro intelectual ligado à "Geração de 70", que acabou adotando uma postura "intermediária" em relação à querela literária.

\section{A intervenção de Ramalho Ortigão}

Entre 1865 e 1866, a querela contou com a intervenção de outros intelectuais que expuseram suas posições sobre os argumentos e posturas adotados em ambos os lados da querela. Como já mencionado, ainda em seu início, Olímpio de Freitas e Germano Vieira Meireles publicaram textos na imprensa periódica defendendo as obras de Antero e Teófilo. Já em 1866, Camilo Castelo Branco, em Vaidades irritadas e irritantes, falou sobre os ataques realizados à obra e à pessoa de Antônio Feliciano de Castilho. Camilo tratou as 
considerações de Antero e Teófilo como desmedidas frente às afirmações realizadas por Castilho, reproduzidas em alguns trechos, e fez uma análise pontual das críticas realizadas em Odes Modernas e Teocracias Literárias, contrapondo-as com suas opiniões acerca da produção literária.

Entretanto, nem todas as opiniões publicadas sobre as temáticas e posturas adotadas na contenda escrita se limitaram à defesa das ideias defendidas por uma ou outra parte. Em janeiro de 1866, Ramalho Ortigão intercedeu na questão com o manifesto Literatura de hoje, no qual teceu críticas dirigidas tanto a Antônio Feliciano de Castilho e àqueles por ele inspirados quanto a Antero de Quental e Teófilo Braga. Ramalho alinhava-se a Antero e Teófilo em relação ao diagnóstico sobre o estado da literatura portuguesa no final do século XIX, mas discordava veementemente da forma como suas críticas foram realizadas e de alguns caminhos propostos para a mudança.

O texto de Ramalho ${ }^{7}$ é iniciado por uma breve consideração sobre a disputa literária que se dava por intermédio da imprensa, passando em seguida ao primeiro segmento de sua análise, dedicada à apreciação da obra Poema da Mocidade de Pinheiro Chagas, a quem considerava um potencial bom escritor, e ao posfácio da obra, escrito que desencadeou a polêmica. Ramalho reconhece a importância que a figura e os escritos de Antônio Feliciano de Castilho teriam desempenhado na literatura portuguesa durante a primeira metade do século, mas considera muitas de suas afirmações realizadas sobre a literatura, o ensino e a sociedade como desconexas com a então atual realidade do país:

A verdade é que o Método repentino é inadaptável nas escolas, donde fugiu há muito tempo; a verdade é que pouquíssimos lêem as soberbas traduções do Sr. Castilho (...) Não acordemos pois do seu pesado sono o sonhador da letra pequena, o sonhador da leitura ensinada com figurinhas e cantilemas, o sonhador das grandes edições largamente pagas e largamente derramadas num pequeníssimo país, onde a maior parte da gente não quer ou não sabe ler. (ORTIGÃO apud FERREIRA e MARINHO, 1988, p.179)

O "método repentino" mencionado tratava-se de um processo de ensino da leitura e escrita desenvolvido por Castilho para aplicação na educação infantil. Este seria, segundo Ramalho, inadaptável e totalmente desalinhado da real necessidade educacional do país, representando o desconhecimento em relação à sociedade portuguesa e o atraso de sua produção intelectual.

\footnotetext{
${ }^{7}$ Devido ao fato da publicação original de Ramalho Ortigão não ter sido obtida até o momento da redação deste texto, utiliza-se aqui a transcrição presente na obra de FERREIRA e MARINHO.
} 
Posteriormente, o apelo realizado por Castilho para que Pinheiro Chagas fosse escolhido para a cadeira de Literatura Moderna é tomado por Ramalho como um insulto ao potencial do próprio escritor e a todos os literatos portugueses, sendo um exemplo claro da “escola de elogios mútuos” que teria se instaurado na construção literária portuguesa:

\begin{abstract}
Sim, Sr Antonio Feliciano: converter um artigo de crítica em carta de empenho para um ministro, obrigar um poeta a figurar como um inválido amparado nos braços do seu editor e do seu crítico (...) é ofender, conspurcuando-a, a dignidade da nobre profissão das letras (...). Aconselhar como professor dum curso superior de literatura (...), requerer que, para satisfação esse empenho, se sobresteja no concurso que há de abrir praça a todos os talentos e a todas as aptidões é ofender a equidade. Eu, que não tenho outro pão além do que me dá a minha humilde mas honrada posição no jornalismo, eu que também sou novo, e também sou marido e pai, em nome da dignidade e do decoro da profissão das letras, em meu próprio nome, em nome do próprio Sr. Pinheiro Chagas, e no de quantos prezam a fidalguia intelectual, protesto aberta e declaradamente contra tão impuro, tão grosseiro e tão aviltante modo de patrocinar o talento independente e honrado. (ORTIGÃO apud FERREIRA e MARINHO, pp.183-184)
\end{abstract}

A indicação ou apadrinhamento do escritor iria contra a noção do "mérito pessoal" da produção intelectual que era tão defendido pelos intelectuais ligados à "Geração de 70". Ao aconselhar a ocupação da vaga sem a devida seleção, Castilho teria, para Ramalho, desrespeitado todos os escritores portugueses e exemplificado a estagnação instaurada na composição literária portuguesa.

Mesmo a posição de Castilho, entretanto, não justificaria, para Ramalho, as posturas de Antero de Quental e Teófilo Braga, que em resposta ao escritor, teriam atacado a figura pessoal do intelectual e utilizado de palavras consideradas por Ramalho como desrespeitosas. Em relação a Antero, a quem considerava "mau poeta" e "mau filósofo" pois "derriba em vez de edificar", e sua Bom senso e Bom gosto, Ramalho demonstrou partilhar de algumas opiniões sobre o estado da produção literária em Portugal, mas não da forma como sua crítica era realizada:

Sou novo como o Sr. Antero de Quental; discordo como ele, e desafogadamente o tenho dito, das sentenças literárias lavradas pelo crítico do D.Jaime e do Poema da Mocidade; prezo como os que mais prezam a liberdade de opinião e o desnodo da verdade, mas repulso com tédio esse valor quando o vejo desenquadrado das questões de arte para se empregar sacriligamente na baixeza plebeia do insulto pessoal descaradamente arremessado à face venerada do decano dos escritores portugueses. (...) Se o Sr. Quental de antemão sabia, como afirma abrindo aí margem a novo 
insulto, que o Sr. Castilho é velho e cego, levará a bem dizer-lhe que maculou o Sr. Quental os vinte e cinco anos com a mais torpe das nódoas que um mancebo pode lançar no seu caráter: a covardia. (ORTIGÃO apud FERREIRA e MARINHO, 1988, p.200)

$\mathrm{O}$ autor apresentava afinidades às opiniões de Antero no que tangia à defesa da liberdade de expressão, mas questionou claramente a maneira como este haveria se portado em alguns pontos de suas réplicas durante a "Questão Coimbrã", ultrapassando a crítica dos posicionamentos literários para se referir diretamente à pessoa de Castilho. $\mathrm{O}$ alinhamento de Ramalho era claro em relação ao conteúdo da crítica, mas não no estilo de sua elaboração em determinados argumentos.

Sobre as considerações de Teófilo realizadas em Teocracias literárias, Ramalho também questionou o que seria uma postura ofensiva do autor e mostrou um entendimento diferente acerca dos sentidos de república e da relação entre "igualdade" e "individualidade" na escrita literária.

\begin{abstract}
Assinando-se contra as teocracias literárias, liga o Sr. Teófilo Braga à velha designação de "república das letras" uma ideia de igualdade, contra a qual me assino eu, eu que nunca pude conciliar tal ideia com o princípio da individualidade e da liberdade. A igualdade de que se não pode sair é um cárcere horrível. O despotismo da igualdade é o mais insuportável e o mais feroz dos despotismos, porque tem a sua origem na vontade dos impotentes, dos estúpidos, e dos insignificantes. Por isso a igualdade não existe. A eliminação da soberania é um sonho irrealizável, enquanto a mão de Deus não reformar o mundo rasorando as preeminências intelectuais, República quer dizer coroa a concurso. O primeiro Bonaparte que existir entre a plebe mete essa coroa na cabeça, e à matula que se lhe for por de lado manda-a metralhar. No domínio das letras é então onde menos eu admito o princípio democrático. A primeira, a mais augusta e a mais inviolável das realezas, é a realeza do gênio. (ORTIGÃO apud FERREIRA e MARINHO, 1988, pp.201-202)
\end{abstract}

Ramalho expôs neste trecho uma percepção da plena igualdade entre os indivíduos, especialmente na qualidade da escrita literária, como uma utopia, inalcançável na realidade. Para ele, haveria uma distinção entre o respeito à individualidade, necessário à elaboração do conhecimento, e uma impossível igualdade entre as produções intelectuais, inexistente devido a uma inevitável superioridade em qualidade de alguns escritos sobre outros. Ramalho também observou perigos em algumas tentativas de estabelecer esta igualdade na prática e, apesar de não fazer menção direta a sua predileção de um regime político sobre outro, cita o 
exemplo da república instaurada na França, cujos eventos posteriores culminaram com a instauração de um Império sob o governo de Napoleão Bonaparte.

Literatura de hoje é um exemplo da pluralidade de opiniões existentes entre os intelectuais ligados à "Geração de 70". Atuando muitas vezes em conjunto na defesa de uma livre reflexão e da instauração de uma urgente transformação em Portugal, alguns destes indivíduos por vezes discordaram sobre quais seriam as causas da decadência portuguesa e, consequentemente, sobre os melhores modelos para operar tal mudança. Tais divergências, que, apareciam apenas em poucos pontos no início de sua produção intelectual, ficaram mais nítidas nas seguintes décadas de suas atuações.

\section{Considerações Finais}

Indubitavelmente, a polêmica literária analisada foi impulsionada, em primeira instância, por questões individuais, sendo um palco utilizado para a pública defesa e ataque das imagens dos escritores envolvidos, assim como de suas obras literárias. Mas por meio do estudo de alguns dos principais textos publicados em sua ocasião, torna-se claro seu emprego para a divulgação de interpretações sobre várias esferas da vida pública de Portugal. Apesar de seu caráter inicialmente estético-literário, acabaram por abordar questões mais amplas relacionadas à situação da sociedade portuguesa oitocentista.

A partir da problemática literária e dos questionamentos pessoais realizados pelos envolvidos, derivaram problematizações que tocavam em pontos centrais da discussão sobre a produção do conhecimento, como o questionamento à reprodução acrítica, uma preocupação maior com o conteúdo do que a forma, a valorização do mérito individual e a liberdade para a defesa de ideias e propostas divergentes às instituídas. Estes elementos transpassavam, por sua vez, outros pontos que seriam várias vezes questionados na atuação da "Geração de 70", como a educação e a influência da Igreja no Estado e no comportamento do povo português.

Em suas intervenções, Teófilo Braga e, especialmente, Antero de Quental apontaram algumas referências dos caminhos que os literatos e governantes portugueses deveriam seguir rumo à superação do estado de decadência do país. Torna-se claro, especialmente através do folhetim Bom senso e bom gosto, que esta intelectualidade observava a França, Inglaterra e Alemanha como modelos a serem seguidos. Destes países advinham as influências teóricas e modelos interpretativos que estes escritores buscavam adaptar e aplicar na problematização de Portugal. 
No que tange à produção literária portuguesa, objeto a partir do qual se desenvolve toda a querela, Antero e Teófilo defenderam a ideia de uma escrita que deveria estar diretamente ligada aos problemas e anseios da sociedade, alinhando-se assim ao que os autores observariam em outros países e atribuindo então uma "função social" à literatura portuguesa. A centralidade deste tema na "Questão Coimbrã", assim como seus desdobramentos para questionamentos sobre outros aspectos da sociedade, expõe a importância da literatura portuguesa não apenas como temática nas discussões destes autores, mas como instrumento para a reflexão e discussão sobre a situação portuguesa.

Partindo de iniciativas individuais, as controvérsias nas quais se envolveram estes intelectuais ganharam notoriedade e desencadearam o início de ações mais diretas no que tange a uma tentativa de mobilização pública para uma transformação sócio-política do país, frente à situação de decadência detectada por eles em Portugal. Os escritos produzidos no âmbito da "Questão Coimbrã" representaram a primeira manifestação pública das discordâncias em relação à forma de se conceber a cultura portuguesa por parte de alguns dos escritores que comporiam a "Geração de 70". A querela demarcou assim o início das atividades da "Geração Nova", que viriam posteriormente a ser desenvolvidas nas suas publicações literárias e periódicas, assim como em suas atuações políticas.

\section{Referências}

BRAGA, Teófilo. As teocracias literárias: relance sobre o estado atual da literatura portuguesa. Lisboa: Tipografia Universal, 1865. Disponível em: https://archive.org/details/bomsensoebomgos00castgoog. Acesso em 18.11.2014

BRAGA, Teófilo. Visão dos tempos. Porto: Em Casa de Viúva Moré - Editora, 1864. Disponível em: http://books.google.com.br/books?id=rOQYAAAAYAAJ\&printsec=frontcover\&hl=pt-

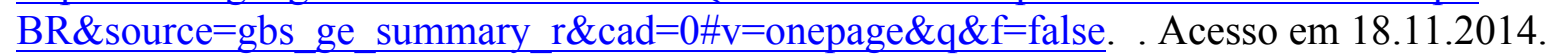

CALAFATE, Pedro. Portugal como problema. Vol. III: Século XIX, A Decadência. Lisboa: Fundação Luso-Americana/Público S.A, 2006.

CHAGAS, M. Pinheiro. Poema da mocidade seguido do Anjo do Lar. Lisboa: Livraria de A.M. Pereira, 1865. Disponível em: https://archive.org/details/poemadamocidades00pinh. Acesso em 18.11.2014.

FERREIRA, Alberto; MARINHO, Maria José. A questão coimbrã (Bom senso e Bom gosto). Coleção Textos Literários. Lisboa: Editoria Comunicações, 1988

HOMEM, Amadeu Carvalho. Do romantismo ao realismo. Temas da cultura portuguesa (Século XIX). Porto: Fund. Eng. Antônio de Almeida, 2005

LOPES, Oscar. SARAIVA, Antônio José. História da literatura portuguesa. $8^{\mathrm{a}}$ Ed. Porto: Porto Editora, 1975. 
MACHADO, Álvaro Manuel. A Geração de 70 - uma revolução cultural e literária. $3^{\circ} \mathrm{Ed}$. Lisboa: Ministério da Educação e Cultura, 1986.

PAREDES, Marçal de Menezes. Configurações luso-brasileiras. Fronteiras culturais, demarcações da história e escalas identitárias (1870-1910). [Saarbrücken]: Novas Edições Acadêmicas, 2013.

PIRES, Antônio Machado. A ideia de decadência na geração de 70. $2^{\circ}$ Ed. Lisboa: Vega, 1992

QUENTAL, Antero de. Bom senso e bom gosto: Carta ao Excelentíssimo Senhor Antônio Feliciano de Castilho por Antero de Quental. Coimbra: Imprensa da Universidade, 1865. Disponível em: https://archive.org/details/bomsensoebomgos00castgoog. Acesso em 18.11.2014.

QUENTAL, Antero de. Odes Modernas. Coimbra: Imprensa da Universidade, 1865. Disponível em: http://books.google.com.br/books?id=mUMuAAAAYAAJ\&printsec=frontcover\&hl=ptBR\&source $=\mathrm{gbs}$ ge summary $\mathrm{r} \& \mathrm{cad}=0 \# \mathrm{v}=$ onepage $\& \mathrm{q} \& \mathrm{f}=$ false. Acesso em 18.11.2014.

ARTIGO ENVIADO EM: 19/03/2015 ACEITO PARA PUBLICAÇÃO EM: 17/04/2015 